\title{
LA INFANCIA EN EL RETRATO ESPAÑOL. UNA MIRADA A LA EMPATÍA EN LA FORMACIÓN DEL PROFESORADO DE EDUCACIÓN PRIMARIA
}

\author{
Gemma Muñoz García ${ }^{1}$ \\ Universidad Complutense de Madrid
}

Esther Jiménez Pablo ${ }^{2}$

Universidad Complutense de Madrid

Recibido 21/04/2020 Aceptado 29/04/2020

\begin{abstract}
Este trabajo pone de relieve el discurso de sectores olvidados por la historiografía y la Historia del Arte, en el marco de la formación del profesorado de Educación Primaria. Se ha seleccionado la infancia como realidad silenciada, y se ha analizado su representación en un género pictórico de gran potencial didáctico, el retrato. El estudio se ciñe especialmente a ejemplos representativos de la Edad Moderna, y más concretamente pertenecientes al ámbito español. Junto al potencial artístico del retrato, a la formación estética y metodológica, se pone en valor la empatía para trabajar y reflexionar sobre el pasado histórico.
\end{abstract}

The aim of this work is to highlight the role of segments forgotten by historiography and Art History, within the framework of the training of Primary Education teachers. Childhood has been selected as a silenced reality, and its representation has been analyzed in a pictorial genre of great didactic potential, the portrait. The study is based on representative examples of the Modern Age, and more specifically belonging to the Spanish sphere. Along with the artistic potential of the portrait, and the aesthetic and methodological training, empathy is highlighted to work and reflect on the past.

DOI

https://doi.org/10.15366/didacticas2020.22.005

PALABRAS CLAVE

Historia del Arte; Educación Primaria; Empatía; Retrato.

Art History; Primary Education; Empathy; Portrait. 


\section{INTRODUCCIÓN}

Cualquiera que sea la rama del conocimiento desde la que se dirija la formación del profesorado, no debería omitir el componente social, humano y emocional. Esta afirmación es especialmente comprometida, si dicha rama del conocimiento alude a las Ciencias Sociales, y más concretamente a las disciplinas vehiculares que dentro de ellas forman parte del currículo educativo durante la educación obligatoria, es decir: Geografía, Historia e Historia del Arte. Particularmente sorprende que la potencialidad de ésta última, a través de las fuentes de estudio que le son propias, no sea utilizada en el ámbito educativo con un mayor aprovechamiento en las aulas. A través del estudio de la obra artística, podemos fomentar la educación estética, la sensibilidad, el conocimiento técnico y formal de la disciplina artística y su contexto histórico. No olvidemos que la sensibilidad y el sentimiento no son innatos, sino que se pueden aprender (Socías, 1996, 9), motivo por el cual, el aprendizaje de la Historia del Arte en la escuela cobra una singular relevancia. Pero, además, queremos favorecer las conexiones emocionales, y la empatía con el alumnado, fomentando el aprendizaje activo, la educación en valores, la creatividad y el pensamiento crítico.

Siguiendo esta línea, el estudio de la obra de arte nos permite acercarnos a realidades diferentes a la nuestra en el espacio y en el tiempo, conocer otras culturas y otras formas de entender el mundo desde concepciones diversas y tolerantes. Además, nos permite poner de relieve aquellos discursos que consciente o inconscientemente la historiografía ha omitido, o minimizado, los discursos de los olvidados (la infancia, la vejez, la mujer, la pobreza, la marginalidad, la discapacidad, o el mundo indígena entre otros) ${ }^{1}$.

Maquet señaló el carácter transversal del arte en todas las culturas (1999, 90-92), al considerar que ilustra las distintas respuestas que el ser humano ofrece a problemas simbólicos, tales como las diversas formas de representación de las creencias, celebraciones y rituales o la vida cotidiana, permitiendo además el desciframiento de los distintos códigos visuales representativos de las diferentes culturas.

Además de los aspectos conceptuales, a los que volveremos más adelante, desde el punto de vista procedimental la obra artística se convierte en una fuente primaria que permite analizar, identificar, e interpretar culturas, aplicar categorías temporales, contrastar datos o realizar análisis estilísticos (Cambil y Tudela, 2017). Metodológicamente por tanto la obra de arte despierta la capacidad de observación, comparación y comunicación, además de favorecer estrategias de análisis, interpretación y sistematización (Trepat, 2003).

Sin duda la enseñanza de la Historia del Arte también posibilita el desarrollo de actitudes relacionadas con la creatividad, la comunicación, la percepción y el respeto hacia las

\footnotetext{
${ }^{1}$ Desde esta perspectiva, un grupo de profesores y profesoras de la Facultad de Educación-Centro de Formación del Profesorado de la Universidad Complutense de Madrid (UCM), desarrollan el Proyecto de Innovación Docente impulsado por el Vicerrectorado de Calidad de la UCM, bajo el título: Aula de memoria: recursos didácticos para recuperar la memoria de los olvidados (16/2019-20), coordinado por la profesora Gemma Muñoz García.
} 
diferentes expresiones artísticas, permitiendo eliminar los preconceptos, estereotipos y prejuicios hacia lo diferente y estableciendo un criterio propio (Fontal, 2006).

Dada la potencialidad didáctica de la Historia del Arte desde sus tres dimensiones: conceptual, procedimental y actitudinal, seleccionamos un género pictórico como el retrato, para rescatar precisamente algunos de esos grupos de olvidados, concretamente la infancia. Acercar al maestro en formación a los niños y niñas de otras épocas y lugares, le permite aproximarse a la Historia de forma empática, priorizando aspectos y narrativas emocionales, partiendo de focos de interés para el alumnado. Desde esta perspectiva, se fomenta un aprendizaje que cuestiona los pilares sobre los que se había asentado la Historia del Arte tradicionalmente, y que J. Thuillier asocia con una forma obsoleta de presentar los contenidos, en base a la explicación de períodos convencionales (2006). Por el contrario, se trataría más bien de impulsar una nueva mirada que vincula la Historia del Arte, con la Historia social y de las mentalidades, y que plantea la narración como hilo conductor para explicar los cambios y las continuidades (Serraller, 2005, citado por Calaf y Fontal, 2010, 33-35).

\section{UNA RELACIÓN POR EXPLORAR: HISTORIA DEL ARTE Y CURRÍCULO}

En términos generales, podemos afirmar que la Historia del Arte tiene una escasa presencia desde el punto de vista curricular en las etapas de Educación Primaria y Secundaria (Roldán, 2016). Pasa a convertirse en una materia optativa con entidad propia en segundo de Bachillerato, a la cual por tanto accederá únicamente alumnado vinculado a las ramas de Artes y Humanidades.

A ello se une el hecho de que los contenidos vinculados con Historia del Arte generalmente son tratados como disciplina subsidiaria de la Historia, quedando limitado su alcance y potencialidad didáctica desde el punto de vista conceptual, procedimental, actitudinal, además de emocional y experiencial. El RD 126/2014, de 28 de febrero, por el que se establece el currículo básico de Educación Primaria, atiende a la expresión plástica del Arte, pero omite su dimensión social e histórica desde las Ciencias Sociales. Éstas afirman integrar "diversas disciplinas que estudian a las personas como seres sociales y su realidad en sus aspectos geográficos, sociológicos, económicos e históricos” (RD 126/2014, BOE, 21), quedando la esfera artística y estética omitida. Sin embargo, buceando en aspectos curriculares concretos, el Bloque 4 dentro del área de Ciencias Sociales, la huella del tiempo, encontramos los conceptos relativos a la medida del tiempo histórico, y establece "la capacidad para ordenar temporalmente algunos hechos históricos (...) utilizando las nociones básicas de sucesión, duración y simultaneidad” (RD 126/2014, BOE, 22), en ello, si bien no se expresa de manera explícita, la Historia del Arte se convierte no sólo en un recurso esencial, sino en una extraordinaria disciplina desde la que apoyarse conceptualmente para facilitar la comprensión del tiempo histórico. Así, la imagen y la expresión gráfica y objetual de diferentes obras artísticas, permite al alumnado "adquirir referencias 
históricas que posibilitarán una interpretación personal del mundo...” (RD 126/2014, BOE, 22).

No olvidemos que, insistiendo en esa potencialidad de la Historia del Arte como disciplina subsidiaria de la Historia, el currículo además añade que "este bloque utilizará mapas y cualquier otra representación gráfica adecuada para la identificación y análisis de procesos históricos, para dar a conocer los procedimientos básicos para el conocimiento de dichas fuentes" (RD 126/2014, BOE, 22). Pero, el Arte y su dimensión social constituyen también un recurso esencial para fomentar la curiosidad en el alumnado por "conocer las formas de vida humana del pasado y valorar la importancia que tienen los restos para el conocimiento y estudio de la historia y como patrimonio cultural que hay que cuidar y legar" (RD 126/2014, BOE, 22).

Así, curricularmente resulta evidente el carácter esencial de la Historia del Arte, desde luego como disciplina subsidiaria de la Historia. Igualmente, es patente su presencia en lo referido a la adopción y difusión del valor patrimonial y de su significatividad como elemento reforzador del sentimiento de herencia cultural. Podría asumirse entonces que fundamentalmente el marco normativo de referencia convierte a la Historia del Arte en un recurso para un mayor y mejor desarrollo de la disciplina histórica, y no como una disciplina en sí misma, con la excepción de la autonomía que adquiere como concepto el patrimonio cultural. De esta forma, la Historia del Arte está presente en gran parte de los contenidos en el área de Historia, especialmente a partir de $4^{\circ}$ curso de Educación Primaria. Como ejemplo baste mencionar el Decreto 89/2014, de 24 de julio, del Consejo de Gobierno, por el que se establece para la Comunidad de Madrid el Currículo de la Educación Primaria, ejemplos concretos como: "identifica algunas huellas culturales de los primeros pobladores de la Península Ibérica, como la Cueva de Altamira", "Conoce la forma de vida de las culturas prerromanas autóctonas de la Península Ibérica (celtas e íberos) e identifica algunos restos de su cultura como la Dama de Elche o los Toros de Guisando", por citar sólo algunos ejemplos (Decreto 89/2014, 30). Además de manera más concreta se explicita a los tres grandes maestros de la Historia del Arte en España de indudable proyección internacional: el Greco y Velázquez en $5^{\circ}$ curso (Decreto 89/2014, p.31) en el marco del conocimiento sobre el Siglo de Oro español, o Goya en $6^{\circ}$ curso de Educación Primaria (Decreto 89/2014, 32).

Sin embargo, a pesar de esta presencia, de manera más evidente, autores como Pol y Asensio $(1996,40)$ señalaban que el arte debe aprenderse de forma explícita, y que su conocimiento, así como la propia formación estética debe ser consecuencia de la instrucción. Por ello resulta paradójico para dichos autores, que los currículos insistan en los grandes objetivos sobre el patrimonio histórico artístico, mientras que decrece la presencia de contenidos puramente artísticos en los mismos.

Estudios posteriores como el ya mencionado de Calaf y Fontal han planteado esa relación entre patrimonio cultural, Historia del Arte y Educación Artística -entre otras disciplinas- como vehículo que permita, desde la transversalidad, generar nuevas concepciones 
y metodologías para la enseñanza del arte en la escuela. Consideran ambas autoras por tanto la importancia de proponerse como meta que la educación artística permita crear patrimonios artísticos. Para Calaf y Fontal la Educación Artística para la Educación Patrimonial implicaría una finalidad constructiva individual y social de lo artístico, una ordenación posmoderna de la enseñanza del arte que incorpore perspectivas como la interculturalidad y la integración del hecho artístico en el cultural (2010, 29-31).

Según esta línea, la necesidad de integrar diferentes disciplinas para un aprendizaje de tipo holístico, parece ofrecer una visión amplia y próxima a la realidad social del alumnado, permitiendo trasladar las concepciones de la Historia del Arte al aprendizaje desde "problemas y situaciones controvertidas de su presente" (tomando como referente a Santiesteban, 2019), desde la mirada al pasado y con el fin de crear referentes sólidos que contribuyan a orientar su futuro.

En definitiva, tras evidenciar la presencia de la Historia del Arte desde el punto de vista normativo, ya sea de manera explícita e implícita, encontramos además un gran espacio en el que la Historia del Arte puede contribuir en el proceso de formación del futuro maestro, la educación en valores, emocional, y más concretamente la empatía. Así, es importante enseñar Arte, pues como afirma Calaf (Calaf, Fontal y Fernández, 2013), en el proceso de desarrollo de la personalidad, el lenguaje artístico es fundamental para el desarrollo de la sensibilidad y el sentido crítico hacia el arte, y en general hacia la vida. Todo ello hace referencia a la base de las competencias fundamentales que todo estudiante debe adquirir en Educación Primaria, Secundaria, y de forma progresiva en la Educación Universitaria (Fuentes y Gil, 2019, 64).

Y precisamente el ámbito competencial es contundente en este sentido, ocupando un espacio que el currículo no termina de desarrollar. Especialmente relevante resulta su presencia en las competencias sociales y cívicas; y de conciencia y expresiones culturales. En cuanto a las dimensiones del saber, saber hacer y saber ser nos encontramos para el caso de la primera aspectos como: comprender los códigos de conducta aceptados en distintas sociedades y entornos, los conceptos de igualdad, no discriminación, comprender las dimensiones intercultural y socioeconómica de las sociedades europeas. En la segunda de las dimensiones, saber comunicarse de manera constructiva en distintos entornos y mostrar tolerancia, y de la tercera, nos interesa señalar la disposición para superar los prejuicios y respetar las diferencias. En todas ellas, la expresión artística puede resultar un recurso esencial y enriquecedor, permitiendo trabajar la imagen de los otros y la imagen propia. Pero es la competencia de conciencia y expresiones culturales, la que con mayor claridad ofrece una visión más integradora de la educación artística en el aula. Lo hace igualmente desde las tres dimensiones formativas del sujeto. Desde el saber, la herencia cultural, los diferentes géneros y estilos de las bellas artes y de las llamadas artes visuales, las manifestaciones artísticas y culturales de la vida cotidiana; partiendo del saber hacer, a través de la aplicación de diferentes habilidades de pensamiento, perceptivas, comunicativas, de sensibilidad y sentido estético y el desarrollo de la creatividad. Y finalmente, desde 
la dimensión del saber ser, encontraríamos el respeto a la diversidad cultural, la valoración de la libertad de expresión, el interés, respeto y valoración crítica por las producciones culturales ${ }^{2}$.

Dada la relevancia de la Historia del Arte, ésta debe ser un elemento esencial en la formación del profesorado, quien además de adquirir el conocimiento de la obra de arte, debe sumar el de las competencias necesarias para instrumentalizar dicho conocimiento guiándolo hacia la acción didáctica, explorando diferentes metodologías y recursos, y abarcando diferentes posibilidades en su tratamiento desde la transversalidad.

\section{INTERPRETAR EL PRESENTE: LA HISTORIA DEL ARTE EN LA FORMA- CIÓN DEL PROFESORADO}

Ya indicábamos que para trasladar al futuro maestro del grado de Educación Primaria la importancia de formar a su futuro alumnado en el conocimiento artístico resulta esencial fomentar la motivación y la curiosidad por aprender, acercando las expresiones artísticas del pasado a situaciones y problemas concretos actuales desde la empatía. De esta forma, encontramos que probablemente resultará más estimulante y significativo trabajar, por ejemplo, el Arte Románico no cómo una sucesión de producciones artísticas, técnicas o datos cronológicos. No porque esta información no sea relevante, sino porque no resulta significativa para el alumnado, y como tal no será interiorizada, analizada, comparada, sintetizada, especialmente en un contexto en el que la información está al alcance de todos fácilmente. Sin embargo, si buscamos acercar dichas expresiones a la idea de cambios y pervivencias culturales, y potenciamos el pensamiento crítico y el tratamiento de todos estos contenidos vinculándolos a intereses del presente de nuestro alumnado, procurando motivar una reacción emotiva, nuestros objetivos de aprendizaje serán más fácilmente alcanzados. La arquitectura románica es un excelente ejemplo de la impronta cultural y artística que el ser humano nos ha legado, pero además es una excusa para reflexionar en torno a rutas de peregrinaje que fomenten la concienciación respecto al turismo sostenible y el emprendimiento. El trágico desenlace de una parte importante de la catedral gótica de Notre Dame tras el incendio ocurrido en 2019 expuso, además de los evidentes daños al patrimonio cultural de la humanidad, el eco recogido por la noticia a través de los medios de comunicación, quienes además fomentaron un movimiento internacional dispuesto a contribuir en el salvamento del templo. Acercarse a las características del Arte Gótico desde esta óptica, permite reflexionar además sobre el poder de los medios de comunicación de masas en la sociedad actual, sobre la importancia que estos dan a según qué patrimonios frente a otros (patrimonio de primera y de segunda), si lo comparamos con el escaso eco recogido en los medios como consecuencia de la destrucción del patrimonio de la localidad de Lorca en Murcia tras el terremoto de 2011. Todo ello permite adentrar al

2 https://www.educacionyfp.gob.es/educacion/mc/lomce/el-curriculo/curriculo-primaria-eso-bachillerato/competencias-clave/competencias-clave.html (recuperado de la WEB del Ministerio de Educación 2 abril 2020) 
alumnado en el valor del patrimonio en la sociedad, en sus implicaciones cuando éste sufre daños importantes, y cómo se pone de manifiesto la importancia de la obra artística como fenómeno identitario. Así como empatizar con qué valor o función tuvo para la sociedad del pasado uno u otro patrimonio, y qué valor o función le estamos asignando a ese patrimonio en el presente.

La apasionante historia de Roma nos permite adentrarnos en otras expresiones artísticas lejos de la decimonónica concepción de las bellas artes. Así, ponemos en valor el mosaico romano, mostrando por ejemplo en éste la representación de un conflicto que se convierte en un espectáculo de ocio a través del mundo de los gladiadores. Empleando como ejemplo el mosaico de gladiadores del Museo Arqueológico Nacional en Madrid, podemos trasladar al presente de nuestro alumnado la reflexión en torno al conflicto en sí, los desencuentros y diferencias entre iguales, y la capacidad para salvar dichas discrepancias. La posición de otros sujetos no participantes activamente en el conflicto, entrando a juzgar e instando a tomar parte ante estas situaciones que después tantos problemas generan en el entorno educativo de los menores.

La vida cotidiana es otro elemento esencial desde el punto de vista historiográfico en los últimos años. Aproximarnos a la microhistoria a través de lo que una obra artística nos muestra, o nos silencia, es motivador para el alumnado, que aprende lenguajes y contextos que tienen que ver con su entorno cotidiano, lo cual le permite empatizar mejor y reflexionar sobre las desigualdades, la gastronomía, los oficios, la indumentaria, la enfermedad, la belleza o la fealdad, la marginación, los transportes o las expresiones populares.

No se trata entonces de no trabajar la Historia del Arte con entidad propia sino de los recursos, estrategias y metodologías que empleemos para acercar dichos contenidos al alumnado, haciéndolos significativos al conectarlos con su realidad actual. Hemos visto algunos ejemplos para trasladar a situaciones del presente contenidos del pasado, que permiten al futuro maestro desarrollar su capacidad crítica y analítica, poniendo el acento en la Historia del Arte. Pero, además, ya adelantábamos la potencialidad de esta disciplina a la hora de trabajar desde el punto de vista emocional. La mayor parte de trabajos publicados en España en este sentido, se han circunscrito a la etapa de Educación Infantil (Moreno, Vera, Miralles y Triguero, 2013; Sarlé, Ivaldi y Hernández, 2014.; Moreno y Vera, 2016), y más concretamente desde el punto de vista no tanto de la Historia del Arte, sino de la educación artística y plástica; recientemente han visto la luz algunos trabajos que ponen de manifiesto la importancia de la enseñanza de la Historia del Arte en Bachillerato, proponiendo una revisión curricular basada en el ámbito competencial (Fuentes y Gil, 2019). Sin embargo, las investigaciones aplicadas a Primaria no son tan abundantes. Especialmente interesantes son aquellas que trabajan desde el ámbito patrimonial la comprensión del presente a través del patrimonio del pasado (Estepa, Cuenca y Martín, 2015), o ejemplos como el de Abad y Ortega (2003) en torno a una experiencia de aula presentando al alumnado diferentes autores (Joan Miró, Joaquín Sorolla, Juan Gris y Pablo Picasso) y 
sus respectivas técnicas pictóricas, fomentando un aprendizaje integral desde la Educación Artística y la Historia del Arte.

Con estos estudios como referencia, y en el marco del Proyecto de Innovación Docente Aula de memoria: recursos didácticos para recuperar la historia de los olvidados, hemos querido poner de relevancia la importancia de educar en empatía al futuro maestro en formación, a través de discursos narrativos que pongan de relevancia la historia de categorías sociales olvidadas. La Historia del Arte, como fuente primaria, puede colaborar y rescatar vestigios de los niños y niñas del pasado a través de la representación pictórica. Habitualmente encontramos que, en las aulas de formación del profesorado, nuestros futuros maestros apenas o nunca tienen relación con niños de las edades con las que desarrollarán su vida profesional al finalizar sus estudios. Por ello, hemos querido rescatar a la infancia del olvido, con el fin de que nuestros maestros en formación conecten socialmente con la realidad de los niños y niñas a lo largo del espacio y el tiempo generando narrativas que podrán desarrollar en el futuro aplicando diferentes metodologías en el aula.

La Historia del Arte acompaña una vez más a la disciplina histórica, partiendo de la noción de empatía histórica (Doñate y Ferrete, 2019, 49-51), y de los beneficios que ésta puede reportar en el aula desde el punto de vista emocional, fomentando la motivación y mejorando la capacidad de comprender y razonar.

\section{HILANDO EMOCIONES A TRAVÉS DEL RETRATO ESPAÑOL}

Esta función social que adquiere la Historia del Arte para interpretar problemas y situaciones de nuestro presente a través del patrimonio histórico artístico, y trabajar en las aulas de formación del profesorado desde el punto de vista emocional, nos acerca a la potencialidad didáctica del retrato. Éste se define como la representación de una persona de manera que pueda ser identificada (Barbe-Gall, 2018, 45), ya que muestra sus rasgos físicos más distintivos y en gran medida simbólicos. Esta representación puede ser más o menos real, o idealizada, pero persigue esencialmente que el retratado individualice al personaje. Este concepto se ampliará a lo largo de la historia, llegando a integrar en los retratos otros elementos, e incluyendo a otros sujetos, o escenas que acompañan al retratado. Este género es una fuente primaria para conocer la sociedad del pasado, adivinar los silencios respecto a grupos sociales, historias particulares y sectores de la población que fueron omitidos de forma más o menos intencionada. Entre dichos sectores, queremos poner de relieve el papel de la infancia, a través de retratos pictóricos infantiles. Proponemos una breve evolución del género, para posteriormente presentar dos propuestas de contenidos y su proyección didáctica en la formación del profesorado de Educación Primaria, a través de dos ejemplos muy diferentes: el retrato de corte y el retrato costumbrista, ambos en la España del s. XVII. 
El retrato es conocido desde la antigüedad clásica a través de manifestaciones escultóricas. Pero es nuestro interés la génesis del retrato como género pictórico, y ésta parte del s. XIV y su posterior evolución hasta mediados del s. XVI, representando individuos en un contexto generalmente religioso (Falomir, 2005, 72). Los monarcas fueron principalmente quienes encargaban estas pinturas, cuyas principales funciones fueron desempeñar un importante papel en negociaciones matrimoniales, así como constituir una "muestra de cariño de padres y allegados más próximos, a sus hijos" (Ruiz, 2005, 102). Eran un ejemplo del poder dinástico y de su sentido aleccionador. En el caso español, será durante el reinado de Felipe II, cuando se dote a las obras pictóricas de una nueva funcionalidad, la decorativa y ornamental, para embellecer el Palacio de El Pardo. Los retratados eran entonces los reyes, reinas, sus familiares, miembros de la corte y humanistas.

Falomir señalaba que, entre la Baja Edad Media y el Renacimiento, "el retrato generó la capacidad de suscitar emociones" $(2005,80)$. Y lo cierto es que, si bien las reacciones emocionales hacia las obras de arte no son homogéneas, sí constituyen una característica esencial de la propia experiencia estética que las caracteriza (Pol, 2006). En definitiva, al individualizar al personaje representado, éste es dotado de significatividad por el mero hecho de ser retratado.

Nos muestra el retrato una serie de elementos visibles, simbólicos, que nos permiten, desde el punto de vista didáctico, motivar al alumnado en la búsqueda de significados ocultos. Ello potencia a la vez el empleo de diferentes estrategias didácticas basadas, por ejemplo, en el aprendizaje por descubrimiento, que en sí misma resulta ya altamente motivadora y emocionalmente productiva en el aula.

Su uso estimula además la intuición, valorando por ejemplo las emociones que nos provoca la intención del autor al emplear una gama cromática u otra, el tratamiento de la luz, el hecho de que ésta sea o no natural, el espacio donde el personaje es retratado -interior o exterior-, la mayor o menor realidad, la idealización o grado de abstracción con que es presentado el personaje, si le vemos el rostro completo de frente o si se nos presenta de perfil. Podemos valorar si el retrato es un busto, si es de medio cuerpo o de cuerpo entero. Qué objetos aparecen y si tienen algún significado simbólico, es algo que el docente debe ayudar a descifrar especialmente. ¿Y qué nos dice la indumentaria, joyas y complementos, insignias, expresión del rostro, el peinado? De esta forma, animamos a nuestro alumnado a iniciarse en una metodología que favorece la observación y el aprendizaje inductivo.

Emociones como la empatía, alegría, tristeza, la soledad, el miedo, la felicidad, el enfado o la vergüenza no son emociones exclusivas del niño y niña de hoy. Iniciamos la búsqueda de estas emociones de la infancia, mirando a la iconografía laica del pasado, que desde el s. XVI se representa principalmente en el retrato de corte. Infantes e infantas cuyos rostros blanquecinos, y con frecuencia inexpresivos, miran desafiantes al espectador, que a su vez tiene que buscar respuestas prestando atención al lenguaje corporal, gestual, y al resto de objetos, personas o animales que aparecen representados. A partir del XVII, junto al re- 
trato de corte, encarnado en la figura Velázquez, encontramos ya representaciones de niños en solitario, generalmente varones, y comienzan a asociarse a escenas de la vida cotidiana. Figuras como José de Ribera o Bartolomé Esteban Murillo nos muestran un rostro menos amable de la realidad, la del niño de la calle, el mendigo, discapacitado, siendo espulgado o hambriento. Niños que transmiten nostalgia, soledad, tristeza, miedo, pero también confianza, alegría y dulzura, destacando el tratamiento y naturalidad con la que son representados. Veremos más adelante precisamente las particularidades de esta representación de la realidad.

Esta tendencia costumbrista se consolida un siglo después, momento en el que además el retrato se acerca también a la sociedad y a las nuevas ideas ilustradas. Así, se representan por un lado familias aristocráticas, como los Duques de Osuna y sus hijos (1787-1788) de Francisco de Goya. Y por otro, escenas costumbristas caracterizadas por un aumento del realismo, cobrando cada vez más protagonismo el niño en la escena, especialmente resaltando la acción durante alguna actividad lúdica. José del Castillo y Goya constituyen en este sentido una fuente inagotable para conocer al niño del s. XVIII, sus juegos y las emociones que en torno a esta actividad se generan. José del Castillo, muestra las ideas pedagógicas ilustradas en las que el estudio de las artes, actividades intelectuales y juegos, especialmente al aire libre, eran esenciales (VVAA, 2000, 113).

Con el inicio de la contemporaneidad se generalizan en toda Europa los retratos de familias aristocráticas y burguesas, hecho que se explica como consecuencia del valor de lo individual que caracteriza a la sociedad en este momento (Díez, 2005, 264). Se difunden las nuevas pautas estéticas del retrato neoclásico, donde destacaría Zacarías González Vázquez, que muestra un estilo clasicista, que se aprecia en el retrato de la Niña Manuela González Velázquez tocando el piano (1820-1821). La inexpresividad es característica de la protagonista, que aparece como adulta prematura, generalmente como consecuencia de la represión del afecto en público (Díez, 2005, 269). Rozando ya el s. XX, se abren las puertas al luminismo de Joaquín Sorolla y sus extraordinarias representaciones de la infancia unidas al contenido social. Así, Triste herencia (1899), nos acerca al mundo de la discapacidad, aspectos que nos permiten trabajar en el aula abordando la solidaridad, la empatía y la lucha por la superación. Las vanguardias, favorecerán el desarrollo de un retrato rupturista, del que constituye buena muestra la representación de Pablo Picasso Niña con muñeca (1938), donde representa a su hija Maya, un estilo ya puramente cubista.

\section{RETRATO CORTESANO Y RETRATO COSTUMBRISTA. LA PROYEC- CIÓN DIDÁCTICA DE LA EMPATÍA}

Trabajar desde un punto de vista didáctico con el retrato infantil de corte tiene ciertas ventajas. Los personajes se pueden reconocer fácilmente, podemos documentarnos sobre la vida del retratado y en qué situación se encontraba la familia real en el momento de ser 
pintado. Por otro lado, la mano del artista siempre goza de prestigio; conocemos las pinceladas, los colores y el juego de luz que utilizaban en sus cuadros Tiziano, Sofonisba o Goya. Y, por último -pensando en que es lo más interesante para trabajar con nuestro alumnado-, en los retratos infantiles de corte la persona retratada suele pintarse acompañada de objetos de gran simbolismo, que proyectan una clara propaganda política hacia el observador. No llega a ser como el retrato de aparato o de Estado (Brown, 2004, 127), en el que la política y el poder son los protagonistas, buscando representar la metáfora, la apariencia y la opulencia, pero sí contiene detalles con distintas lecturas. Hay que tener en cuenta que el retrato infantil en la corte tenía dos funciones muy claras: por un lado, dar a conocer el crecimiento del retratado. Tenemos la evolución física de algunos príncipes, princesas o infantes desde que tenían uno o dos años porque se enviaban a otras cortes para mantener el contacto familiar. Es el caso del continuo intercambio de retratos entre las dos ramas de los Austrias, entre Madrid y Viena (Cobo, 2016, 144-145). Y por el otro, los matrimonios de la realeza eran concertados, con intereses políticos y patrimoniales, que fomentaron el intercambio de retratos entre cortes europeas desde que los futuros contrayentes eran niños. Estos retratos preparaban el futuro sello del contrato matrimonial, aumentaban el vínculo familiar entre los futuros contrayentes, y corroboran la buena salud de ambos (la fecundidad en el caso de ellas).

Ahora bien, el problema de trabajar en didáctica con el retrato de corte aparece desde el punto de vista de las emociones y la empatía. Atendiendo a los rostros, parece que este retrato, concretamente en la Monarquía Hispana de época Moderna, carece de sentimientos y son inexpresivos. Les falta toda la emotividad que sí podemos contemplar o intuir en las miradas y gestos del retrato costumbrista de la época. En el caso de los retratos infantiles de corte, no sabemos si el futuro príncipe o la infanta eran felices, si estaban tristes, si sufrían, si tenían hambre, si solían jugar, o si les estaba permitido llorar. Pero en lo invisible está la clave y los objetos nos proporcionan datos más personales y humanos que rodean al personaje.

Analicemos un retrato de corte desde el punto de vista de la empatía histórica. Buena parte de este análisis didáctico se puede extrapolar a otros cuadros infantiles de corte. Se trata del retrato del infante Felipe Próspero que Diego Velázquez pintó en 1659 para enviar a la corte de Viena. Un lienzo de 128,5 x 99,5 cm que se expone en el Kunsthistorisches Museum de Viena (n ${ }^{\circ}$ inv. 319). Comenzamos por una breve descripción del cuadro. Lo primero que llama la atención es su rostro; impasible, sin gesto ni mueca, consiguiendo el pintor fijar así todos los detalles de la fisionomía, que se repite en todos los retratos de corte de época Moderna. Su mano derecha se apoya en una silla, siendo este gesto típico en estos retratos para dar un mínimo de movilidad a la rígida postura, y mostrar todas las partes del cuerpo que el posado de medio perfil podría dejar oculto. Su tez es muy blanquecina que, como señalan distintos autores, mostraría la frágil salud del retratado (Prohaska, 2004, 126). No obstante, a poco que se compare con otros retratos se verá que las élites, y más la realeza, tenían la piel muy clara, reflejo de su vida palaciega sin trabajar 
en el exterior ni tener conceptos más actuales que acreditan belleza a una piel más morena. En cuanto a su vestimenta, el príncipe lleva la falda sobre enaguas, sin corpiño ni lechuguilla porque es un niño, con un delantal blanco por encima.

En el análisis de los siguientes elementos encontramos los sentimientos y podemos llegar a empatizar con las circunstancias del personaje. Sobre el blanco del delantal destacan un total de cinco amuletos y talismanes. Entre los amuletos se puede identificar el coral y una higa de azabache y entre los talismanes observamos los que tienen forma de una mano con puño cerrado, unos cuernos y una campanilla de oro. Todos están sujetos con cordeles alrededor del delantal, y ceñidos a la ropa. Probablemente estos amuletos y talismanes sea lo que más llame la atención del cuadro, inmortalizando en la pintura la búsqueda de la protección del pequeño príncipe (Horcajo, 1999, 522). He aquí el miedo y la angustia por proteger al pequeño que sentían sus padres. Si nos situamos en el contexto, Felipe IV tenía una necesidad imperiosa de dar un heredero a la corona, tan sólo le sobrevivió unos años un varón de su primera esposa, Isabel de Borbón. El tan deseado heredero, el príncipe Baltasar Carlos, falleció a los diecisiete años. Y desde entonces los hijos varones, tanto de su primera como de su segunda esposa, fallecían en el parto o a los pocos días o meses de haber nacido. El protagonista de nuestro retrato posaba con dos añitos, y era la garantía de continuidad de la dinastía. El miedo de los reyes, y de la corte en general, a no concebir un hijo varón se expresa en este cuadro, donde el niño no va engalanado ni mostrando un alto estatus en su pomposa vestimenta, sino que muestra el detalle de unos elementos que reflejan el ruego y el deseo de la pervivencia del niño. Amuletos y talismanes que evitan el mal de ojo, protegen al que los lleva y alejan a los malos espíritus que rondan la muerte, como es el caso del sonido de las campanillas cuando el niño se mueve. El propio nombre del príncipe nos evoca no a una riqueza próspera, sino al deseo de que prospere su vida y pueda reinar. La mortalidad infantil en el siglo XVII era muy elevada, y en el ambiente cortesano se explicaba por la endogamia, la juventud de las reinas, los embarazos continuos, la presión de dar herederos, la atención en el parto o la medicina. Desafortunadamente ese miedo de la familia de Felipe IV a que falleciera el heredero se hizo efectivo antes de cumplir los cuatro años, en 1661, tan sólo dos años después de que le pintara Velázquez.

Destacamos en la sobriedad del fondo negro del cuadro, los distintos tonos rojizos que utiliza el pintor. Y la tímida luz que penetra por un ventanal que no resta protagonismo al retratado, al contrario, ilumina su figura. Es preciso subrayar la falta de elementos que acompañan a lo que hoy identificamos con la infancia: los juguetes. En la corte, estos retratos reflejan a pequeños adultos, cuya seriedad y actitud quieren evocar cierta autoridad. Tenemos algún retrato con juguetes como caballitos de palo, algunos espadines, que muestran un juego, pero que en realidad se trata de la formación cortesana de los niños. Era bastante común, por ejemplo, pintar a las infantas o princesas con rosarios en las manos, pues su función en la corte cuando se esposaban con reyes o príncipes era más espiritual y de intercesoras entre la divinidad y los vasallos. 
Lo que sí es más común, y en este cuadro aparece, es la incorporación de animales en la escenografía del cuadro. Y en este caso se pinta a un perrillo faldero, blanco y canela, con unos ojos saltones y una cara cuyo hocico apoya para descansar en el reposabrazos. Un perro de mirada melancólica, han querido ver algunos autores, que ahondan en querer ver un cuadro con códigos tristes y trágicos, como si fuera algo premonitorio. Sin embargo, Velázquez ha pintado numerosos canes, en ocasiones con miradas atentas al espectador, consiguiendo así múltiples interpretaciones y que hoy nos sigamos preguntando qué nos quiere decir el animal con sus ojos. Los perros pintados siempre se muestran fieles; los más grandes y esbeltos eran para el retrato de caza de los reyes, pero a los niños se les acompañaba de perros pequeños, accesibles, juguetones, de interior, en definitiva, de perros falderos que son los que tenían en la corte las reinas y los niños y niñas (Rodríguez, 2016). El perro añade por tanto un elemento de domesticidad, de hogar, de palacio, e incluso de lujo. En esta época las clases bajas no se podían permitir perros falderos que divirtiesen a la familia, sino que los perros ayudaban al trabajo. Un siglo antes, los cuadros infantiles mostraban animales de compañía del Amazonas, pájaros y monos, que reflejaban el poderío territorial de Felipe II (Morales, 1992). Pensemos por ejemplo en las infantas de Sánchez Coelho o de Sofonisba. Sin embargo, en el caso que nos ocupa, y especialmente siendo el pintor Velázquez, la autoridad y poderío de Felipe IV, que estaba en crisis y decadencia, da paso a la simplicidad de un niño cuyo gesto sobrio y serio le prepara para el gobierno de una Monarquía, con la esperanza de que sobreviviera.

A diferencia del retrato cortesano, en el costumbrista no identificamos claramente al personaje retratado. Si bien suele representarse a personajes individualizados y que responden a modelos reales, estos nos muestran situaciones cotidianas de las que formaba parte el pueblo en general. De esta manera, el personaje encarnaba el sentir y cotidianeidad de muchos individuos anónimos. Bartolomé Esteban Murillo (1617-1682) representó con gran maestría este retrato costumbrista de su Sevilla natal durante el Siglo de Oro, mostrando una gran habilidad para captar el carácter psicológico de sus personajes. Muchos de estos fueron niños, debido a la gran predilección del autor por la infancia. Fueron protagonistas en escenas narrativas de tipología religiosa, pero miramos en esta ocasión a su representación laica, popular, en retratos que muestran la pobreza en sus diferentes manifestaciones, con niños jugando, comiendo, acompañados por un adulto, siendo espulgados o despiojados. En estas escenas, se adivina cierto carácter piadoso del ideal religioso, que dan como resultado personajes amables y encantadores (Vadillo, 2017, 49), mostrando por tanto cierta idealización de esa marginalidad. Esta miseria, extendida fuera de la corte como consecuencia precisamente de la decadencia económica y política que vivía la España de Felipe IV, tuvo un especial azote en Sevilla donde se unió la elevada mortalidad ocasionada por la peste en 1649, que hizo crecer la pobreza, el hambre y la desesperanza.

Frente a este panorama, generalmente los niños de Murillo muestran vitalidad y alegría, no se ocultan las emociones a diferencia de lo que acontece en el retrato cortesano. De hecho, Murillo captó en algunos de sus cuadros una de las expresiones humanas de mayor 
dificultad de ejecución pictórica, la risa (Vadillo, 2017, 51). Pero además la nostalgia, el asombro, la diversión, la duda o la complicidad. Una de las obras que muestran esta emoción de alegría, y risa es Muchacho con perro (1650-1655), que se encuentra actualmente en el Museo del Hermitage en San Petersburgo, y que fue pintado en la misma época aproximadamente que el retrato de Felipe Próspero de Velázquez. Muchacho con perro nos muestra a un niño sonriendo, en una escena en exterior, en la que todo el protagonismo lo tiene el joven, en este caso algo mejor vestido que los típicos pícaros callejeros característicos del autor. Seguramente va o viene de hacer un recado, y muestra su mirada de complicidad, simpatía y bondad hacia un perro que juguetea e interactúa con él en la esquina inferior izquierda de la imagen, y al que parece dedicar un gesto con su mano derecha de no tener nada que ofrecerle, con una entrañable sonrisa. En la obra de Murillo, la representación de perros fue también una constante, mostrando en este caso la complicidad y sagacidad entre el muchacho y el can (Morales, 1992, 268). Su otra mano, está ocupada asiendo un canasto con un recipiente cerámico en el interior, contenedor de aquello que el muchacho ha ido a buscar.

La imagen de niños y pícaros, en ocasiones niños huérfanos que vivían en la calle y que con gran astucia y picardía salían adelante, fue perfectamente inmortalizada por Murillo (Valdivieso, 2018, 63-68). Niños que vivían al límite de la ley asaltando huertos para alimentarse, o que recibían unas monedas por hacer recados, son los que Murillo pinta. Introduce esos tintes de cruda realidad, siempre con gesto delicado y amable, como si la más terrible de las desdichas, la soledad, el hambre, el miedo, siempre hubieran de hacerse frente con una sonrisa y esperanza.

La vida callejera que refleja Murillo en su obra, y que apreciamos en Muchacho con perro a través de representaciones en exteriores, es otro elemento que nos distancia del retrato de corte. Los niños de Murillo viven a la luz del sol, sus rostros están sonrojados y se aprecian, a pesar de las penurias y la escasez, saludables.

Trabajar didácticamente con Muchacho con perro, incluso con otros niños de Murillo, nos adentra en un verdadero mundo de emociones y posibilidades para trabajar desde la empatía. Nuestros niños actuales pueden conocer y comparar otras realidades distanciadas en el tiempo y en el espacio, apreciar cambios y pervivencias culturales, mirar al pasado apreciando la simpatía de estos niños, que seguramente con muchas más necesidades muestran y reconocen sus emociones, las mismas que los niños de hoy sienten. Podemos preguntarnos qué haríamos en su lugar, cómo afrontaríamos una adversidad, y tomar como ejemplo la determinación y lucha por su supervivencia.

\section{CONCLUSIONES}

La Historia del Arte constituye sin lugar a duda una disciplina esencial en la formación del profesorado. Aporta sentido estético y valoración desde un punto de vista formal del patrimonio histórico- artístico y cultural de nuestro entorno, muy especialmente de aquel 
que conforma nuestro sentido identitario. Nos permite acercarnos, a través de diferentes metodologías, recursos, estrategias y técnicas, al concepto de empatía histórica, permitiendo trazar una línea entre el presente y el pasado, con el fin de conocer y dar explicación a situaciones y problemas actuales, para poder orientar nuestro futuro. Todo ello nos invita a buscar nuevas fórmulas desde las que acercar al futuro maestro los contenidos, a fin de hacerlos más significativos, permitiendo crear un nuevo modelo de aprendizaje.

El género del retrato, concretamente en el ámbito pictórico, individualiza al retratado, permitiendo al observador conocer a personajes de otras épocas, adentrándose en sus vidas y como si de un puzle se tratara, ir recomponiendo los distintos aspectos simbólicos que el autor ha escondido bajo su pincel. Ello permite adentrarnos en el mundo de las emociones en general, constituyendo un recurso de primer orden, con el que acercar al alumnado contenidos histórico-artísticos desde un plano emocional, y sumando nuevas metodologías en la enseñanza de la Historia del Arte, desde planteamientos más próximos a los propios intereses del alumnado. La contraposición del retrato cortesano y el retrato costumbrista y de vida cotidiana durante el Barroco, encarnado en las grandes figuras de Velázquez y Murillo permiten, al enfatizar este enfoque, conocer no sólo características propias del estilo Barroco en la pintura del XVII, sino acercarse a la Historia, la Historia del Arte, y a la infancia, desde la empatía histórica, aunando desde la transversalidad, diferentes focos de interés, y favoreciendo le interés del alumnado atendiendo a uno de sus focos de interés, el niño. Ello nos permite generar debates en torno a los aspectos expuestos, pero incluso abrir otros que el propio retrato silencia. Por ejemplo, el porqué de la escasa presencia de niñas en el retrato costumbrista.

\section{REFERENCIAS}

ABAD, E. y ORTEGA, N. (2003): "La creación artística vista por los ojos de un niño". En Íber, Didáctica de las Ciencias Sociales: Geografía e Historia, 37.

BARBE-GALL, F. (2018): Cómo hablar de arte a los niños. Donostia: Nerea.

BROWN, J. (2004): La Monarquía Española y el retrato de aparato de 1500 a 1800. En El retrato. Barcelona: Galaxia Gutenberg

CALAF, R. y FONTAL, O. (2010): Cómo enseñar arte en la escuela. Madrid: Síntesis.

CALAF, R., FONTAL, O. y FERNÁNDEZ, A. (2013): Arte para todos. Miradas para enseñar y aprender el patrimonio. Gijón: Trea.

CAMBIL, M.E. y TUDELA, A. (Coords.) (2017): Educación y patrimonio cultural. Fundamentos, contextos y estrategias didácticas. Madrid: Pirámide.

COBO, G. (2016): "Entre Viena y Madrid: intercambios de retratos en la familia Habsburgo durante el siglo XVII”. En BSAA arte 82, pp. 143-166. 
DÍEZ, J.L. (2005): El retrato español del s. XIX: el triunfo de un género. En Portús, J. (Ed). El retrato español. Del Greco a Picasso. Museo Nacional del Prado.

DOÑATE, O. y FERRETE, C. (2019): "Vivir la historia. Posibilidades de la empatía histórica para motivar al alumnado y lograr una comprensión efectiva de los hechos históricos”. En Didáctica de las Ciencias Experimentales y Sociales, 36 (pp. 47-60).

ESTEPA, J., CUENCA, J.M. y MARTÍNEZ, M. (2015): "La enseñanza de las sociedades actuales e históricas a través del patrimonio. Enseñando el presente a través del pasado en educación primaria”. En Íber, Didáctica de las Ciencias Sociales: Geografía e Historia, 79 (pp.33-40).

FALOMIR, M. (2005): Los orígenes del retrato en España. De la falta de especialistas al gran taller. En Portús, J. (Ed.) El retrato español. Del Greco a Picasso. Museo Nacional del Prado.

FONTAL, O. (2006): "Los contenidos actitudinales en la enseñanza de la Historia del Arte". En En Íber, Didáctica de las Ciencias Sociales, Geografía e Historia, 49.

FUENTES, C. y GIL, N. (2019): "La didáctica de la Historia del Arte y la educación competencial. Propuesta de replanteamiento curricular”. En Enseñanza de las Ciencias Sociales: Revista de investigación, 18, pp.63-75. UAB: Barcelona.

HORCAJO, N. (1999): “Amuletos y talismanes en el retrato del príncipe Felipe Próspero de Velázquez”. En Archivo español de Arte 72/288, pp. 521-530.

MAQUET, J. (1999): La experiencia estética. La mirada de un antropólogo sobre el arte. Madrid: Celeste Universidad.

MORALES, F (1992): "Los perros en la pintura". En Laboratorio de Arte, 5, Tomo 1, pp. 265-274.

MORENO, J.R., VERA, M.I., MIRALLES, P. y TRIGUEROS, F.J. (2013): "El retrato en Educación Infantil: Una propuesta didáctica sobre arte”. En Clío \& Asociados (17), 249-266. En Memoria Académica.

MORENO, J. R. y VERA, M.I. (2016): "Retrato, autorretrato e identidad en educación infantil”. En Revista Estudios, 32. Universidad de Costa Rica.

POL, E. y ASENSIO, M. (1996): "El aprendizaje de los estilos artísticos, Emprender y enseñar Historia del Arte”. En Íber Didáctica de las Ciencias Sociales, Geografía e Historia, $n^{\circ} 8$, pp. 25-42.

POL, E. (2006): "La recepción del arte”. En Íber, Didáctica de las Ciencias Sociales: Geografía e Historia, 49.

PROHASKA, W. (2004): El Kunsthistorisches Museum de Viena: La pinacoteca. LondresMunich: Scala Publishers-Verlag C.H. Beck oHG, vol. 2. 
RODRÍGUEZ, I. (2016): "Los canes de Felipe III: Una aproximación a través de los oficios de la Real Caza de Montería (1598-1621)”. En Libros de la Corte, 13, pp. 50-66.

ROLDÁN, A. (2016): La disciplina histórico-artística desde la experiencia. Un caso aplicable a Educación Primaria y Secundaria. En Didáctica de las Ciencias Sociales. Fundamentos, contextos y propuestas (Dir. A. Liceras y G. Romero). Madrid: Pirámide.

RUIZ, L. (2005): Retratos de corte en la monarquía española (1530-1660). En Portús, J. (Ed). El retrato español. Del Greco a Picasso. Museo Nacional del Prado.

SANTIESTEBAN, A. (2019): "La enseñanza de las Ciencias Sociales a partir de problemas sociales o temas controvertidos: estado de la cuestión y resultados de una investigación”. En El futuro del pasado, 10, pp. 57-79.

SARLÉ, P., IVALDI, E. y HERNÁNDEZ, L. (2014): Arte, educación y primera infancia: sentidos y experiencias. Organización de Estados Iberoamericanos: Madrid.

SOCÍAS, I. (1996): "El valor del arte y la renovación de la didáctica en las Ciencias Sociales”. En Íber, Didáctica de las Ciencias Sociales, Geografía e Historia, 8, pp. 7-16.

THUILLER, J. (2006): Teoría general de la Historia del Arte. México: Fondo Cultura Económica.

TREPAT, C.A. (2003): "Didácticas de la Historia del Arte. Criterios para una fundamentación teórica”. En Íber, Didáctica de las Ciencias Sociales, Geografía e Historia, 37.

VVAA. (2000): Goya y la pintura española del siglo XVIII. Museo del Prado. Español.

VADILLO, M. (2017): Murillo y lo contemporáneo. En Cat. Exposición: Murillo y la Facultad de Bellas Artes de Sevilla cuatrocientos años después. Sevilla: Universidad de Sevilla.

VALDIVIESO, E. (2018): “Semblanza de la vida y obra de Murillo”. En Crítica, 1028, pp.613.

RD 126/2014, de 28 de Febrero, por el que se establece el currículo básico de Educación Primaria [Enlace], recuperado el 26 de noviembre de 2019.

BOCM (Decreto 89/2014) de 24 de julio, del Consejo de Gobierno, por el que se establece para la Comunidad de Madrid el Currículo de la Educación Primaria. [Enlace] recuperado el 26 de noviembre de 2019. 